\title{
L'économie de l'esclavage colonial . Enquête et bilan du XVIIe au XIXe siècle
}

\section{Bernard Gainot}

\section{Q OpenEdition \\ 1 Journals}

\section{Édition électronique}

URL : https://journals.openedition.org/ahrf/1868

DOI : 10.4000/ahrf.1868

ISSN : 1952-403X

Éditeur :

Armand Colin, Société des études robespierristes

\section{Édition imprimée}

Date de publication : 1 décembre 2004

Pagination : 180-181

ISSN : 0003-4436

\section{Référence électronique}

Bernard Gainot, "L'économie de l'esclavage colonial . Enquête et bilan du XVIIe au XIXe siècle »,

Annales historiques de la Révolution française [En ligne], 338 | octobre-décembre 2004, mis en ligne le 22 mars 2006, consulté le 24 avril 2022. URL : http://journals.openedition.org/ahrf/1868 ; DOI : https:// doi.org/10.4000/ahrf.1868

Ce document a été généré automatiquement le 24 avril 2022.

Tous droits réservés 


\title{
L'économie de l'esclavage colonial . Enquête et bilan du XVIIe au XIXe siècle
}

\author{
Bernard Gainot
}

\section{RÉFÉRENCE}

Fred Célimene et André Legris (dir.), L'économie de l'esclavage colonial . Enquête et bilan du XVIIe au XIXe siècle, Paris, CNRS Éditions, 2002, 181 p., ISBN 2-271-06076-1, $22 €$.

1 Il s'agit d'un recueil d'articles, qui tournent autour des questions que se posent les économistes de la fin du XVIIIe et du début du XIXe siècles. Sachant que l'économie coloniale de l'époque moderne (ou " colonisation moderne ») repose sur le " paradigme sucrier» - monoculture sucrière, grande plantation, main d'œuvre servile -, par quoi va-t-on le remplacer dès lors que l'un de ses éléments structurants - l'esclavage - a disparu, ou est condamné à disparaitre à terme ? Sachant encore que cette disparition n'est pas seulement moralement, mais économiquement souhaitable, le travail salarié étant supposé plus rentable que le travail servile? Les grandes références de cette réflexion sont Adam Smith, Jean-Baptiste Say et Sismonde de Sismondi.

Christian Schmidt replace l'argument esclavagiste dans la perspective des théories contractualistes, de Hobbes à Jérémy Rawls. Il rappelle que cet argument esclavagiste est parfaitement accepté par les philosophes du droit naturel, dès lors qu'il s'inscrit dans un contrat; pacte de soumission contre pacte d'association. Les philosophes du XVIIIe siècle, Montesquieu, Locke et Rousseau, s'attachent à réfuter cette inscription de l'esclavage au cœur du Contrat social ; non sans contradictions (le pacte maître-esclave remplacé par la domination de la collectivité sur le contactant isolé). L'auteur cherche à dépasser la contradiction par une application de la théorie moderne des jeux.

3 Michel Herland expose le glissement, dans les théories des adversaires de l'esclavage, de l'argument moral à l'argument économique. Dans une vaste perspective, il part de la 
légitimation de l'institution esclavagiste chez Aristote, centrée sur l'infériorité morale des esclaves, pour arriver à la réfutation d'Adam Smith, centrée sur la supériorité du travail salarié sur le travail servile, en termes de coûts de production.

4 Les textes d'Adam Smith, et particulièrement Les leçons de jurisprudence, sont précisément analysés par André Lapidus. L'analyse économique seule (l'absence de rentabilité du travail servile) ne suffit pas à rendre compte des raisons de la survie du système. Les maîtres compensent la moindre profitabilité par la libido de la domination. L'abolition de l'esclavage suppose donc la prise en compte du complexe culturel de la relation maitre-esclave, à travers la mise en place de contre-pouvoirs qui ne sont pas posés par le strict calcul économique.

5 Cette question de la transition d'un type de système à un autre est analysée par les penseurs libéraux qui succèdent à Adam Smith. Richard Arena expose les diverses façons dont trois d'entre eux, et non des moindres, Jean-Baptiste Say, Sismonde de Sismondi et Pellegrino Rossi envisagent cette transition. Ils s'interrogent sur les formes de persistance du système confronté à son efficacité relative.

6 C'est à un autre théoricien du problème colonial que s'intéresse Philippe Steiner, Tocqueville. Repartant de la position libérale classique de la supériorité du travail salarié, il constate que la transition ne peut se faire que par un fort volontarisme du pouvoir métropolitain. Ce qui est aussi une façon de prendre acte des limites du calcul économique strict, et de la nécessité de prendre en compte les facteurs sociaux, culturels, mais aussi et surtout politiques.

7 Pierre Dockès retrace toute l'évolution du "paradigme sucrier », la persistance d'une structure à trois dimensions - la grande plantation, le travail servile, la technologie du moulin à sucre - et son évolution à travers le temps et l'espace, depuis le sud de la Mésopotamie aux Antilles, en passant par les îles de la Méditerranée et Madère.

8 Fred Célimène et André Legris s'attachent à la description de la structure dans le domaine où elle connut sa pleine expansion, les Caraïbes. Elle rencontre un cadre commercial qui est celui du mercantilisme. C'est à la confrontation d'échelles que se livrent les deux auteurs, la micro-économie de la firme, et la macro-économie des échanges.

9 Hai-Quang-Ho rappelle enfin que le paradigme sucrier s'implanta également aux Mascareignes, et expose les problèmes de la transition du travail servile au travail salarié à la Réunion, entre 1828 et 1853.

10 Dans une introduction à toutes ces contributions, Célimène et Legris replacent ces débats économiques dans une perspective historique et idéologique, qui est celle du mouvement abolitionniste dans la période 1750-1850.

11 En clair, c'est un ouvrage très riche, très documenté, qui apporte une contribution décisive à l'histoire de l'esclavage, et de son abolition dans le monde occidental. 